\title{
ĐÁNH GIÁ MỘT SỐ TÍNH CHẤT CƠ BẢN CỦA ĐẤT BÁN NGẬP THEO CAO TRİNH NGẬP TẠI KHU VỤ̉C LÒNG HỒ THỦY ĐIỆN SƠN LA
}

\section{Evaluating some basic nature of half flooded land based on water level in entrails of reservoir of Son La hydroelectric plant}

Ngày nhận bài: 15/1/2017; ngày phản biện: 20/1/2017; ngày duyệt đăng: 22/3/2017

\section{Trần Thị Phả, Trần Văn Điền, Đàm Xuân Vận, Hoàng Quý Nhân* \\ Nguyễn Văn Giáp **}

\section{TÓM TẮT}

Kết quả nghiên cứu tại khu vực lòng hồ, cho thấy các tính chất đất có sự khác nhau rõ rệt

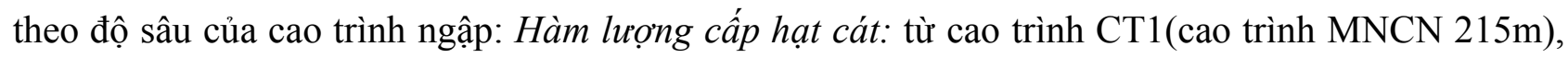
xuống cao trình CT2 (cao trình $190-195 \mathrm{~m}$ ) tăng, từ cao trình CT2 xuống Cao trình CT3 giảm, từ cao trình CT3 (cao trình ngập từ $175-190 \mathrm{~m}$ ), xuống cao trình CT4 (Cao trình MNC 175m), tăng, hàm lương cấp hạt limon: trung bình tại các cao trình nghiên cứu lại ngược lại với các thành phần hạt cát, dao động từ 31,50 - 58,52\%. Trong đó ở vị trí lớn nhất là CT3 (cao trình ngập từ 175 $190 \mathrm{~m})$ và thấp nhất ở cao trình CT1. Về hàm luợng cấp hạt sét: trung bình tại các cao trình nghiên cứu dao động từ 19,48 - 29,37\%. Trong đó vị trí lớn nhất tại CT1 (cao trình ngập 215m). Cao trình có hàm lượng sét thấp nhất là $\mathrm{CT} 4$, Về tính chất đất, ở cao trình $\mathrm{CT} 1$ (cao trình $\mathrm{MNCN} 215 \mathrm{~m}$ ), và cao trình (cao trình 190 - 195m), thể hiện tính chất cơ bản là đất chua, nghèo dinh dưỡng, hàm lượng mùn, đạm có xu hướng tích tụ theo độ sâu, cation kiềm, ở mực thấp hơn các cao trình sau, hàm lượng $\mathrm{Al}^{3+}$, tăng dần đến cao trình 190 -195m. Đối với cao trình CT3 (cao trình ngập từ 175 $190 \mathrm{~m}$ ), và cao trình CT4 (Cao trình MNC 175m), Thể hiện sự lắng đọng chất dinh dưỡng do vậy $\mathrm{pH}$, tăng dần, và các chất dinh dưỡng tăng dần đến mực nước chết, hàm lượng mùn, đạm có xu hướng tích tụ giảm dần theo độ sâu,cation kiềm, giảm dần đến mực nước chết, hàm lượng $\mathrm{Al}^{3+}$, giảm dần.

Từ khóa: Đất bán ngập, cao trình ngập, tính chất đất, vùng hồ, thủy điện Sơn La.

\begin{abstract}
The results showed that soil properties at the bottom of the Lake differ significantly according to water level: Sand particles content: from CT1 water level $(215 \mathrm{~m}$ water level: The highest water level) down to water level of CT2 (190 - 195m water level) has increased, from water level CT2 to water level CT3 has decreased, from water level CT3 (175-190m water level flooded) to water level CT4 ( $175 \mathrm{~m}$ dead water level) has increased. Limon particles content: this study shows that the average water level is opposed to grains of sand components, ranged from 31.50 to $58.52 \%$. In which the largest is CT3 (from 175 - 190m flooded water levels) and the lowest water level is CT1. Clay content: The average water levels in this research ranged from 19.48 to $29.37 \%$. In which, the largest at CT1 (215m water level flooded). The water levels of the lowest levels of clay is CT4. Soil

\footnotetext{
* Đại học Nông Lâm - Thái Nguyên

•*ại học Tân Trào
} 
property indicates that at water level CT1 (The highest water level) and water level CT2 (190$195 \mathrm{~m}$ water level), shows the basic properties of soil is acid, poor nutrition, humus and nitrogen content, tend to accumulate according to depth, alkali cation, in the lower level of the following water level. A13+ concentration increased gradually from $190 \mathrm{~m}$ to $195 \mathrm{~m}$. CT3 (of the submerged from 175 - 190m) and CT4 (175m Dead water level) illustrate the deposition of nutrients $\mathrm{pH}$ has increased gradually to the dead water level, humus and nitrogen content tends to accumulate decreases with depth, Alkali cation dropped slightly to the level of dead water, A13+ concentration has decreased steadily.

Keywords: Wetlands half, water level flooded, soil properties, Hydropower reservoir, Son La hydroelectric.

\section{I. Đặt vấn đề}

Đất vùng bán ngập là phần diện tích đất thuộc vùng lòng hồ thủy điện, thủy lợi nhưng không bị ngập nước thường xuyên, thời gian bị ngập nước trong năm tùy thuộc vào quy trình vận hành của từng hồ nhưng không quá sáu (06) tháng, thời điểm ngập xác định được[4].

Nhà máy điện Sơn La kéo dài khoảng $200 \mathrm{~km}$ từ huyện Mường La tỉnh Sơn La đến huyện Mường Lay tỉnh Điện Biên, hồ chứa ngập khoảng 23.000ha đất tự nhiên trong đó có 10.000 ha đất bán ngập. Đồng thời dẫn đến hình thành môi trường sinh thái mới, với hệ thống các cơ cấu về không khí, thổ nhưỡng, động - thực vật, nước, trong đó con người là nhân tố đặc biệt. Nó được hình thành và thích nghi dần ổn định trong một thời nhất định nào đó. Ngoài ra dựa vào nhu cầu về năng lượng, về nông nghiệp, mà nhà máy thủy điện điều chỉnh cho phù hợp với nhu cầu đó, từ đó dẫn đến mực nước được điều tiết ngập và lên xuống theo cao trình, từ mực nước chết $175 \mathrm{~m}$, đến mực nước cao nhất là $215 \mathrm{~m}$. Ở mỗi một cao trình lại có những đặc điểm tính chất khác nhau, và câu hỏi đặt ra là ở những cao trình đó khác nhau như thế nào? mực nước ngập có tác động gì đến tính chất đất ở cao trình đó? các câu hỏi về sự sa lắng, xói mòn tại các cao trình được đặt ra.

\section{I. Đối tượng và phương pháp nghiên cứu}

\section{1. Đối tượng nghiên cứu}

- Đối tương nghiên cúu về cao trình ngập

+ Cao trình MNCN 215m

+ Cao trình 190 - 195m

+ Cao trình 175 - 190m

+ Cao trình MNC175m

\section{- Đối tượng phân tích}

$\mathrm{pH}$, Đạm tổng số, Mùn tổng số (\%OM), $\mathrm{K}_{2} \mathrm{O}$ dễ tiêu, $\mathrm{P}_{2} \mathrm{O}_{5}$ dễ tiêu, $\mathrm{Ca}^{2+}, \mathrm{Mg}^{2+}, \mathrm{Al}^{3+}$, và thành phần cấp hạt

\subsection{Phương pháp nghiên cứu}

- Phuoong pháp lấy mẫu đất

Mẫu đất tại các khu vực nghiên cứu được lấy ở tầng mặt có độ sâu từ $0-20 \mathrm{~cm}$, trên diện tích đất bán ngập. Các mẫu đất sau khi lấy được đựng vào các túi riêng, có ghi kí hiệu ngoài bao bì.

- Phương pháp phân tích trong phòng thí nghiệm

+ Phương pháp xử lý mẫu

Mẫu đất: Sau khi lấy về loại bỏ rễ cây, tạp chất, hong khô trong không khí ở nhiệt độ phòng sau đó đem nghiền qua rây $1 \mathrm{~mm}$.

+ Phương pháp phân tích 
Xác định các chỉ tiêu trong đất bằng những phương pháp có độ chính xác cao và thường được dùng phổ biến hiện nay trong các phòng phân tích đất ở Việt Nam. Các phương pháp cụ thể như sau:

Xác định thành phần cấp hạt của đất theo TCVN 8567:2010 (Chất lượng đất - phương pháp xác định thành phần cấp hạt)

\section{Kết quả và thảo luận}

\subsection{Phân chia môi trường đất bán} ngập tại lưu vực thủy điện Sơn La

Trên cơ sở chế độ điều tiết mực nước hồ theo mùa và theo từng tháng trong năm, căn cứ đường biểu đồ cho thấy tương quan giữa mực nước hồ và cao trình ngập tại các tháng trong năm

- Từ tháng 9 đến tháng 12 mực nước hồ ở MNCN là 215m;

- Từ tháng 1 nước bắt đầu rút, đến tháng 3 mực nước đạt đến cốt 190 - 195m;

- Từ tháng 4 đến cuối tháng 6 nước rút nhanh đạt $\mathrm{MNC}$ là $175 \mathrm{~m}$;

- Từ tháng 7 đến giữa tháng 8 mực nước hồ giữ ở mức $175 \mathrm{~m}$

- Thời gian ngập nước trong khoảng tù tháng 9 đến tháng 12 mực nước hồ ở cao nhất là $215 \mathrm{~m}$ :
Ở cao trình này thời gian hở đất là 4 tháng, đất ở cao trình cao nhất. Đất bán ngập ở trong thời kỳ chưa ngập nước, người dân sử dụng đất để canh tác, trồng hoa màu..., nhưng với tỉ lệ ít.

Về đặc điểm đất ở đây là đất bị xói mòn rửa trôi nhiều do đất tương đối dốc. Ngoài ra vùng này ở cao trình cao nhất mà thời gian hở đất cao nhất, nên người dân tận dụng đất để trồng trọt, trong quá trình sử dụng đất có sử dụng các chất, vô cơ, hữu cơ như: phân đạm, lân, phân chuồng, đặc biệt là thuốc bảo vệ thực vật, vì quá trình nước ngập lên nó sẽ làm ngập toàn bộ diện tích đất trồng trọt đó và các chất hữu cơ, hóa học, các thiên địch, sâu bệnh hại đều bị hòa vào nước và dẫn đền đưa ra các khu vực khác là lắng xuống đáy hồ, và kéo theo sạt lở khi nước rút, vì vậy ở khoảng thời gian này đất thường bạc màu, ít chất dinh dưỡng độ mùn thấp, đất có tính chất cơ bản là chua.

- Thời gian ngập nước trong khoảng tì̀ tháng 1 đến tháng 3 mưc nước đạt đến cột 190 - 195m: Thời gian hở đất ở cao trình này là 3 tháng cộng thêm 4 tháng của cao trình $215 \mathrm{~m}$ nữa thì đất ở đây cơ bản là giống thời gian ngập nước ở thời gian một, nhưng một số khu vực ở đây, được bồi lắng phù sa ở các vùng trũng thấp do mực nước rút ở cao trình trước, một số khu vực bị xói mòn rửa trôi.

Bảng 1: Khung thời gian hở đất theo tháng và cao trình đối với vùng đất bán ngập thủy điện Sơn La

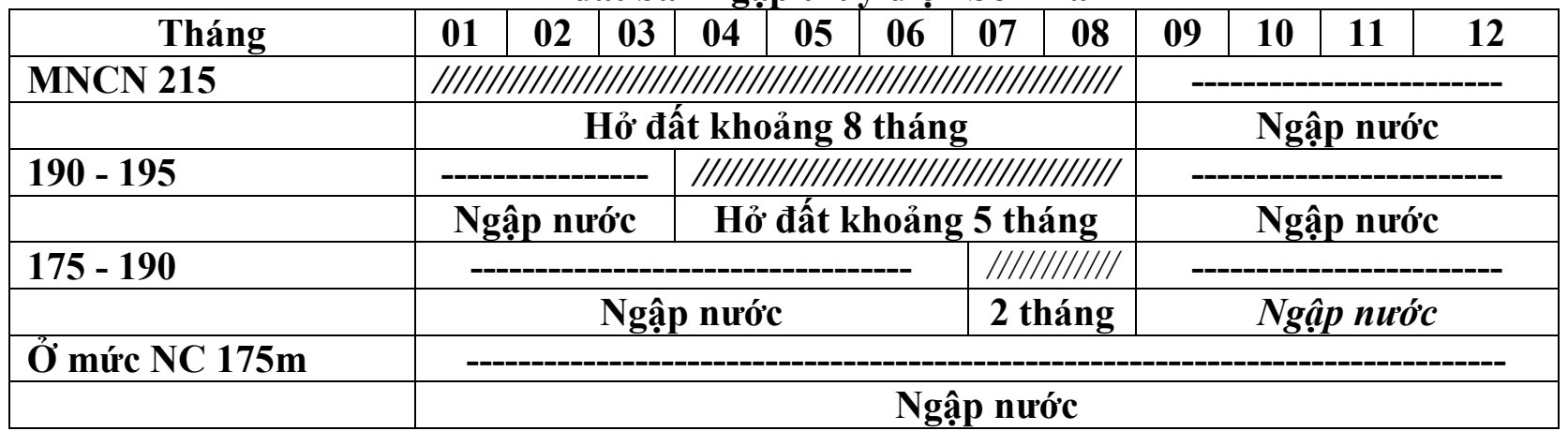


Đặc điểm đất có một số khu vực có độ dốc cao thì đất bạc màu, ngược lại một số vùng trũng thấp thì đất có dinh dưỡng cao, nhưng đất cũng chứa một số thành phần hóa học các chất vô cơ, hữu cơ, tàn dư bảo vệ thực vật...,

- Thời gian khoảng tù̀ tháng 4 đến cuối tháng 6 mưc nước rút nhanh xuống $175 \mathrm{~m}$ :

Trong thời gian này đất được giữ lại một lượng đất phù sa, đất mầu mỡ, thành phần mùn cao, $\mathrm{pH}$ lớn vì nó có thời gian ngập nước lâu, chất dinh dưỡng được giữ lại một phần, đất ở đây có một số các thành phân ô nhiễm các chất vô cơ, hữu cơ trộn lẫn vào nhau, do quá trình trồng trọt, đất cơ bản có màu đen.
- Thời gian khoảng tù tháng 7 đến tháng 8 mưc nước chết $175 \mathrm{~m}$

Đất bán ngập ở vùng này là sự lắng đọng phù sa, cơ bản có chất dinh dưỡng, thành phần mùn, $\mathrm{pH}$ lớn vì thời gian ngập nước lâu, chứa nhiều thành phần ô nhiễm có tính chất phức tạp, vì được rửa trôi, ở trên xuống, đất ở đây không được người dân sử dụng để trồng trọt.

\section{2. Đặc điểm tính chất đất theo cao} trình ngập

3.2.1 Kết quả phân tích thành phần cấp hạt của bán ngập theo cao trình ngập tại các khu vục lòng hồ thủy điện Sơn La

Bảng 2: Phân tích thành phần cấp hạt theo cao trình ngập

\begin{tabular}{|c|c|c|c|c|c|}
\hline \multirow{2}{*}{$\begin{array}{l}\text { Địa điểm } \\
\text { lấy mẫu }\end{array}$} & \multirow{2}{*}{$\begin{array}{l}\text { Cao } \\
\text { trình }\end{array}$} & \multirow{2}{*}{$\begin{array}{l}\text { Kí hiệu } \\
\text { mâ̂u }\end{array}$} & \multicolumn{3}{|c|}{$\begin{array}{c}\text { Thành phần cấp hạt \% } \\
\text { TCVN } 8567: 2010\end{array}$} \\
\hline & & & $\begin{array}{c}\text { Cát } \\
2-0.02 \mathrm{~mm}\end{array}$ & $\begin{array}{c}\text { Limon } \\
0.02-\mathbf{0 . 0 0 2} \mathbf{~ m m}\end{array}$ & $\begin{array}{c}\text { Sét } \\
<0.002 \mathrm{~mm}\end{array}$ \\
\hline \multirow{4}{*}{ Ít Ong } & CT1 & Đ1 & 39,14 & 31,51 & 29,35 \\
\hline & $\mathrm{CT} 2$ & Đ2 & 42,72 & 31,54 & 25,74 \\
\hline & CT3 & Đ3 & 16,83 & 58,51 & 24,66 \\
\hline & CT4 & Đ4 & 28,47 & 52,06 & 19,47 \\
\hline \multirow{4}{*}{ Mường Trai } & CT1 & Đ5 & 39,11 & 31,52 & 29,37 \\
\hline & $\mathrm{CT} 2$ & Đ6 & 42,72 & 31,53 & 25,75 \\
\hline & CT3 & Đ7 & 16,85 & 58,50 & 24,65 \\
\hline & CT4 & Đ8 & 28,46 & 52,07 & 19,47 \\
\hline \multirow{4}{*}{ Mường Sại } & $\mathrm{CT} 1$ & Đ9 & 39,13 & 31,55 & 29,32 \\
\hline & $\mathrm{CT} 2$ & Đ10 & 42,76 & 31,51 & 25,73 \\
\hline & CT3 & Đ11 & 16,80 & 58,56 & 24,64 \\
\hline & CT4 & Đ12 & 28,45 & 52,06 & 19,49 \\
\hline \multirow{4}{*}{ Cà Nòng } & $\mathrm{CT} 1$ & Đ13 & 39,12 & 31,51 & 29,37 \\
\hline & $\mathrm{CT} 2$ & Đ14 & 42,77 & 31,50 & 25,73 \\
\hline & CT3 & Đ15 & 16,86 & 58,52 & 24,64 \\
\hline & CT4 & Đ16 & 28,49 & 52,02 & 19,49 \\
\hline
\end{tabular}

Chú thich:

CT1: Vị trí lấy mẫu ở cao trình MNCN 215m. Đ1, Đ5, Đ9, Đ13

CT2: Vị trí lấy mẫu ở cao trình 190 - 195m. Đ2, Đ6, Đ10, Đ14

CT3: Vị trí lấy mẫu ở cao trình $175-190 m$. Đ3, Đ7, Đ11, Đ14

CT4: Vị trí lấy mẫu ở cao trình MNC 175m. Đ4, Đ8, Đ12, Đ14 
- Hàm lượng cấp hạt cát: Qua bảng và biểu đồ ta thấy hàm lượng cấp hạt cát từ cao trình $\mathrm{CT} 1$ xuống cao trình $\mathrm{CT} 2$ tăng, từ cao trình $\mathrm{CT} 2$ xuống $\mathrm{Cao}$ trình $\mathrm{CT} 3$ giảm, từ cao trình CT3 xuống cao trình CT4 tăng, cụ thể:

+ TT Ít Ong, cao trình CT1 là 39,14\% giảm xuống CT2 là 42,72\%, từ CT2 xuống CT3 còn $16,83 \%$, từ CT3 xuống CT4 tăng lên được $28,47 \%$.

+ Xã Mường Trai cao trình CT1 là $39,11 \%$ giảm xuống $\mathrm{CT} 2$ là $42,72 \%$, từ $\mathrm{CT} 2$ xuống CT3 còn $16,85 \%$, từ CT3 xuống CT4 tăng lên được 28,46\%.

+ Xã Mường Sại, cao trình CT1 là $39,13 \%$ giảm xuống CT2 là 42,76\%, từ CT2 xuống CT3 còn $16,80 \%$, từ CT3 xuống CT4 tăng lên được 28,45\%.

+ Xã Cà Nòng, cao trình CT1 là $39,12 \%$ giảm xuống CT2 là $42,77 \%$, từ CT2 xuống CT3 còn $16,86 \%$, từ CT3 xuống CT4 tăng lên được 28,49\%.

- Đối với hàm luợng cấp hạt limon: Trung bình tại các cao trình nghiên cứu lại ngược lại với các thành phần hạt cát, dao động từ $31,50-58,52 \%$. Trong đó ở vị trí lớn nhất là CT3 (cao trình ngập từ $175-190 m$ ) và thấp nhất ở cao trình CT1.

+ TT Ít Ong, cao trình CT1 là 31,51\% xuống CT2 là 31,54\%, từ CT2 xuống CT3 tăng được $58,51 \%$, từ $\mathrm{CT} 3$ xuống $\mathrm{CT} 4$ là $52,06 \%$.

+ Xã Mường Trai, cao trình CT1 là 31,52\% xuống CT2 là 31,53\%, từ CT2 xuống
CT3 tăng được 58,50\%, từ CT3 xuống CT4 là $52,07 \%$.

+ Xã Mường Sại, cao trình $\mathrm{CT} 1$ là $31,55 \%$, xuống CT2 là $31,51 \%$, từ CT2 xuống CT3 tăng được 58,56\%, từ CT3 xuống CT4 là $52,06 \%$.

+ Xã Cà Nòng, cao trình CT1 là $31,51 \%$, xuống $\mathrm{CT} 2$ là $31,50 \%$, từ CT2 xuống CT3 tăng được 58,52\%, từ CT3 xuống CT4 là $52,02 \%$.

- Về hàm luợngcấp hạt sét: Trung bình tại các cao trình nghiên cứu dao động từ 19,48 - 29,37\%. Trong đó vị trí lớn nhất tại CT1 (cao trình ngập $215 \mathrm{~m}$ ). Cao trình có hàm lượng sét thấp nhất là CT4.

+ TT Ít Ong, cao trình CT1 là 29,35\% xuống $\mathrm{CT} 2$ là $25,74 \%$, từ $\mathrm{CT} 2$ xuống $\mathrm{CT} 3$ là 24,66\%, từ CT3 xuống CT4 là 19,47\%.

+ Xã Mường Trai, cao trình CT1 là $29,37 \%$ xuống CT2 là $25,75 \%$, từ CT2 xuống CT3 còn $24,65 \%$, từ CT3 xuống CT4 là $19,47 \%$.

+ Xã Mường Sại, cao trình CT1 là $29,32 \%$ xuống CT2 là $25,73 \%$, từ $\mathrm{CT} 2$ xuống $\mathrm{CT} 3$ còn $24,64 \%$, từ $\mathrm{CT} 3$ xuống $\mathrm{CT} 4$ là $19,49 \%$.

+ Xã Cà Nòng, cao trình CT1 là 29,37\% xuống $\mathrm{CT} 2$ là $25,73 \%$, từ $\mathrm{CT} 2$ xuống $\mathrm{CT} 3$ còn 24,64\%, từ CT3 xuống CT4 là 19,49\%.

\subsubsection{Kết quả phân tích tính chất đất} bán ngập theo cao trình ngập nuớc tại các khu vục lòng hồ thủy điện Sơn La

Bảng 3: Phân tích tính chất đất theo cao trình ngập nước

\begin{tabular}{|c|c|c|c|c|c|c|c|c|c|c|}
\hline $\begin{array}{l}\text { Địa điểm } \\
\text { lấy mẫu }\end{array}$ & $\begin{array}{c}\text { Cao } \\
\text { trình }\end{array}$ & $\begin{array}{c}\text { Kí } \\
\text { hiệ̣u } \\
\text { mâ̂u }\end{array}$ & pH & $\begin{array}{c}\text { Đạm } \\
\text { ts } \\
(\mathrm{mg} / \mathrm{g} \\
)\end{array}$ & $\begin{array}{l}\begin{array}{c}\text { Mùn } \\
\text { ts } \\
(\% O\end{array} \\
\text { M) }\end{array}$ & $\begin{array}{c}\mathrm{K}_{2} \mathrm{O} \\
\mathrm{dt} \\
(\mathrm{mg} / \mathrm{k} \\
\mathrm{g})\end{array}$ & $\begin{array}{c}\mathrm{P}_{2} \mathrm{O}_{5} \\
\mathrm{dt} \\
(\mathrm{mg} / \\
100 \mathrm{~g}) \\
\end{array}$ & $\begin{array}{l}\mathrm{Ca}^{2+} \\
(\mathrm{meq} / \\
100 \mathrm{~g})\end{array}$ & $\begin{array}{l}\mathrm{Mg}^{2+} \\
(\mathrm{meq} / \\
\mathrm{l00g})\end{array}$ & $\begin{array}{c}\mathrm{Al}^{3+} \\
(\mathrm{cmol} / \mathrm{k} \\
\mathrm{g})\end{array}$ \\
\hline \multirow{4}{*}{ Ít Ong } & CT1 & Đ1 & 5,55 & 1,23 & 0,66 & 47,52 & 2,44 & 3,58 & 0,91 & 0,17 \\
\hline & CT2 & Đ2 & 4,14 & 1,39 & 1,97 & 39,16 & 4,13 & 2,21 & 0,36 & 0,95 \\
\hline & CT3 & Đ3 & 3,95 & 2,24 & 2,15 & 49,14 & 3,15 & 2,68 & 0,93 & 0,47 \\
\hline & CT4 & Đ4 & 5,19 & 1,58 & 1,98 & 54,16 & 6,53 & 5,97 & 0,79 & 0,10 \\
\hline \multirow{4}{*}{$\begin{array}{l}\text { Mường } \\
\text { Trai }\end{array}$} & CT1 & Đ5 & 5,25 & 1,22 & 0,68 & 47,43 & 2,46 & 3,59 & 0,89 & 0,17 \\
\hline & CT2 & Đ6 & 4,24 & 1,48 & 2,01 & 39,15 & 4,23 & 2,22 & 0,45 & 0,98 \\
\hline & CT3 & Đ7 & 4,17 & 2,21 & 2,17 & 49,21 & 3,12 & 2,68 & 0,53 & 0,46 \\
\hline & CT4 & Đ8 & 5,39 & 1,55 & 1,95 & 54,17 & 6,48 & 5,98 & 0,87 & 0,09 \\
\hline
\end{tabular}




\begin{tabular}{|c|c|c|c|c|c|c|c|c|c|c|}
\hline \multirow{4}{*}{$\begin{array}{c}\text { Mường } \\
\text { Sại }\end{array}$} & CT1 & Đ9 & 5,56 & 1,18 & 0,63 & 47,43 & 2,39 & 3,69 & 0,99 & 0,18 \\
\cline { 2 - 12 } & CT2 & Đ10 & 4,23 & 1,46 & 1,87 & 39,21 & 4,23 & 2,34 & 0,44 & 0,93 \\
\cline { 2 - 11 } & CT3 & Đ11 & 4,43 & 2,11 & 2,16 & 49,23 & 3,12 & 2,54 & 0,96 & 0,48 \\
\cline { 2 - 11 } & CT4 & Đ12 & 5,54 & 1,51 & 2,08 & 54,34 & 6,49 & 5,89 & 0,84 & 0,09 \\
\hline \multirow{4}{*}{ Cà Nòng } & CT1 & Đ13 & 5,38 & 1,23 & 0,75 & 46,42 & 2,46 & 3,60 & 0,93 & 0,18 \\
\cline { 2 - 11 } & CT2 & Đ14 & 4,12 & 1,52 & 1,98 & 38,06 & 4,09 & 2,24 & 0,40 & 0,94 \\
\cline { 2 - 10 } & CT3 & Đ15 & 4,18 & 2,31 & 2,16 & 50,04 & 3,07 & 2,69 & 0,91 & 0,46 \\
\cline { 2 - 10 } & CT4 & Đ16 & 5,36 & 1,49 & 1,88 & 54,34 & 6,53 & 5,87 & 0,81 & 0,09 \\
\hline
\end{tabular}

Chú thich:

CT1: Vị trí lấy mẫu ở cao trình MNCN 215m. Đ1, Đ5, Đ9, Đ13 CT2: Vi trí lấy mẫu ở cao trình 190 - 195m. Đ2, Đ6, Đ10, Đ14 CT3: Vi trí lấy mẫu ơ cao trình $175-190 m$. Đ3, Đ7, Đ11, Đ14 CT4: Vị trí lấy mẫu ở cao trình MNC 175m. Đ4, Đ8, Đ12, Đ14

- Về hàm lượng $p H$, ta thấy cao trình (CT1) tương ứng với cao trình cao nhất $215 \mathrm{~m}$, có hàm lượng $\mathrm{pH}$ ở mức chua vừa, và cũng cao hơn các cao trình khác, dao động với cao trình thấp nhất trung bình là 1,46 . Khi ở độ cao trình thấp hơn thì $\mathrm{pH}$ giảm của thể: CT2 (cao trình $190-195 \mathrm{~m}$ ) có $\mathrm{pH}$ trung bình đạt 4,18 ở mức chua nhiều, cùng với đó ở cao trình kế tiếp sau đó là CT3 (cao trình 175 - 190m) có $\mathrm{pH}$ trung bình tại bốn vị trí lấy đạt 4,18 ở mức chua nhiều. Khi trong cao trình ở mực nước chết CT4 có pH trung bình tại bốn vị trí lấy đạt 5,37 ở mức chua vừa.

- Đất có phản úng chua nhiều, chua it, hàm luợng $\mathrm{Al}^{3+}$ trao đổi trong đất rất thấp và thấp cu thể: Hàm lượng $\mathrm{Al}^{3+}$ thấp là $\mathrm{CT} 1$ (cao trình 215m), với CT4 (cao trình MNC 175m) $\mathrm{pH}$ thể hiện mức $\mathrm{pH}$ trung bình giữa các vị trí lấy đạt từ $5,37-5,55$ ở mức chua vừa nên có hàm lượng $\mathrm{Al}^{3+}$ ở mức thấp, và thấp hơn trung bình giữa các vị trí đạt từ 2,75 - 5,5 lần, hai cao trình có hàm lượng $\mathrm{pH}$ từ 4,18 , thể hiện $\mathrm{pH}$ mức chua nhiều đồng nghĩa với việc hàm lượng nhôm di động ở mức cao, ở CT2 (cao trình $190-195 \mathrm{~m}$ ) trung bình giữa bốn vị trí lấy đạt $0,95(\mathrm{cmol} / \mathrm{kg}$ ), CT3 (cao trình từ 175 $190 \mathrm{~m})$ trung bình đạt $0,47(\mathrm{cmol} / \mathrm{kg})$ ở mức cao nhất.

\section{- Hàm lương đạm theo cao trình ngập}

Hàm lượng Đạm tổng số ở cao trình CT1 ở mức trung bình. Các cao trình CT2, CT3, CT4 hàm lượng đạm tổng số dao động từ 1,53 -2,22(mg/g), thể hiện hàm lượng đạm tổng số ở mức khá.

+ TT Ít Ong, cao trình $\mathrm{CT} 1$ là $1,23(\mathrm{mg} / \mathrm{g})$, giảm xuống CT2 là $1,39(\mathrm{mg} / \mathrm{g})$ từ CT2 xuống CT3 tăng lên đạt 2,24(mg/g), từ CT3 xuống CT4 giảm xuống còn 1,58( $\mathrm{mg} / \mathrm{g})$.

+ Xã Mường Trai, cao trình $\mathrm{CT} 1$ là $1,22(\mathrm{mg} / \mathrm{g})$, giảm xuống CT2 là $1,48(\mathrm{mg} / \mathrm{g})$ từ CT2 xuống CT3 tăng lên đạt 2,21 (mg/g), từ CT3 xuống CT4 giảm xuống còn 1,55(mg/g).

+ Xã Mường Sại, cao trình $\mathrm{CT} 1$ là $1,18(\mathrm{mg} / \mathrm{g})$, giảm xuống CT2 là $1,46(\mathrm{mg} / \mathrm{g})$ từ CT2 xuống CT3 tăng lên đạt 2,11(mg/g), từ CT3 xuống CT4 giảm xuống còn 1,51(mg/g).

+ Xã Cà Nòng, cao trình CT1 là $1,23(\mathrm{mg} / \mathrm{g})$, giảm xuống CT2 là $1,52(\mathrm{mg} / \mathrm{g})$, từ CT2 xuống CT3 tăng lên đạt 2,31( $\mathrm{mg} / \mathrm{g})$, từ CT3 xuống CT4 giảm xuống còn 1,49(mg/g).

- Hàm lương Mùn theo cao trình ngập

Hàm lượng mùn tổng số tăng theo cao trình cụ thể;

+ TT Ít Ong, cao trình CT1 là 0,66\% xuống CT2 tăng đạt $1,97 \%$, từ CT2 xuống CT3 tăng đạt 2,15\%, từ CT3 xuống CT4 giảm còn $1,98 \%$. 
+ Xã Mường Trai, cao trình $\mathrm{CT} 1$ là 0,68\% xuống CT2 tăng đạt 2,01\%, từ CT2 xuống CT3 tăng đạt 2,17\%, từ CT3 xuống CT4 giảm còn $1,95 \%$.

+ Xã Mường Sại, cao trình CT1 là 0,63 \% xuống CT2 tăng đạt 1,87 \%, từ CT2 xuống CT3 tăng đạt 2,16\%, từ CT3 xuống CT4 giảm còn $2,08 \%$.

+ Xã Cà Nòng, cao trình CT1 là 0,75 \% xuống CT2 tăng đạt 1,98 \%, từ CT2 xuống CT3 tăng đạt 2,16 \%, từ CT3 xuống CT4 giảm còn $1,88 \%$.

Có thể nói do quá trình ngập lên xuống, xẩy ra quá trình phân hủy các thực vật, động vật, khi ngập nước, khi nước rút đồng thời xẩy ra quá trình sa lắng xuống vì vậy hàm lượng mùn tổng số tăng dần khi nước rút.

- $\mathrm{Hàm}$ lượng $\mathrm{K}_{2} \mathrm{O}$ và $\mathrm{P}_{2} \mathrm{O}_{5}$

Hàm lượng $\mathrm{K}_{2} \mathrm{O}$ dễ tiêu đa phần nằm ở mức rất nghèo cụ thể như sau: Ở ba cao trình tính từ cao trình $\mathrm{MNCN} 215 \mathrm{~m}$ xuống thì hàm lượng kali dễ tiêu có hàm lượng ở mức rất nghèo. Cùng với đó ở CT4 có hàm lượng kali dễ tiêu ở mức nghèo. Cụ thể:

+ TT Ít Ong, cao trình CT1 xuống CT2 xuống CT3 lần lượt là 47,52, 39,16, 49,14(mg/kg), hàm lượng kali dễ tiêu ở mức rất nghèo. Cao trình $\mathrm{CT} 4$, hàm lượng kali dễ tiêu ở mức nghèo đạt 54,16(mg/kg).

+ Xã Mường Trai, cao trình CT1 xuống CT2 xuống CT3 lần lượt là 47,43, 39,15, 49,21(mg/kg), hàm lượng kali dễ tiêu ở mức rất nghèo. Cao trình $\mathrm{CT} 4$, hàm lượng kali dễ tiêu ở mức nghèo đạt 54,17(mg/kg).

+ Xã Mường Sại, cao trình CT1 xuống CT2 xuống CT3 lần lượt là 47,43, 39,21, 49,23(mg/kg), hàm lượng kali dễ tiêu ở mức rất nghèo. Cao trình $\mathrm{CT} 4$, hàm lượng kali dễ tiêu ở mức nghèo đạt 54,34(mg/kg).

+ Xã Cà Nòng, cao trình CT1 xuống CT2 xuống CT3 lần lượt là 46,42, 38,06, 50,04(mg/kg), hàm lượng kali dễ tiêu ở mức rất nghèo. Cao trình $\mathrm{CT} 4$, hàm lượng kali dễ tiêu ở mức nghèo đạt 54,34(mg/kg).

Hàm lượng $\mathrm{P}_{2} \mathrm{O}_{5} \mathrm{dt}$ ở mức rất nghèo, và nghèo, được thể hiện như sau:

+ TT Ít Ong, cao trình CT1 xuống CT2 xuống CT3 lần lượt là 2,44, 4,13, 2,68(mg/100g), hàm lượng lân dễ tiêu ở mức rất nghèo. Cao trình $\mathrm{CT} 4$, hàm lượng kali dễ tiêu ở mức nghèo đạt $6,53(\mathrm{mg} / 100 \mathrm{~g})$.

+ Xã Mường Trai, cao trình CT1 xuống CT2 xuống CT3 lần lượt là 2,46, 4,23, $3,12(\mathrm{mg} / 100 \mathrm{~g})$, ở mức rất nghèo. Cao trình $\mathrm{CT} 4$, hàm lượng kali dễ tiêu ở mức nghèo đạt $6,48(\mathrm{mg} / 100 \mathrm{~g})$.

+ Xã Mường Sại, cao trình CT1 xuống CT2 xuống CT3 lần lượt là 2,39, 4,23, 3,12(mg/100g), hàm lượng lân dễ tiêu ở mức rất nghèo. Cao trình $\mathrm{CT} 4$, hàm lượng kali dễ tiêu ở mức nghèo đạt $6,49(\mathrm{mg} / 100 \mathrm{~g})$.

+ Xã Cà Nòng, cao trình CT1 xuống CT2 xuống CT3 lần lượt là 2,46, 4,09, $3,07(\mathrm{mg} / 100 \mathrm{~g})$, hàm lượng lân dễ tiêu ở mức rất nghèo. Cao trình $\mathrm{CT} 4$, hàm lượng kali dễ tiêu ở mức nghèo đạt $6,53(\mathrm{mg} / 100 \mathrm{~g})$.

- Hàm lượng $\mathrm{Ca}^{2+}, \mathrm{Mg}^{2+}$

Các $\mathrm{Ca}^{2+}$ trao đổi thấp và trung bình dao động trung bình trong khoảng 2,25 5,93(meq/100g) đất, tại cao trình CT1 (cao trình $\mathrm{MNCN} 215 \mathrm{~m}$ ) ta thấy hàm lượng $\mathrm{Ca}^{2+}$ cao và theo cao trình sau thể hiện giảm dần mức giao động từ 0,97 - 1,37 lần, nguyên nhân do sự xói mòn rửa trôi trong ở hai vùng ngập từ cao $\mathrm{CT} 2$ đến $\mathrm{CT} 3$, và khi nước rút đến mực nước chết thì hàm lượng $\mathrm{Ca}^{2+}$ lại tăng từ 3,28 3,68 lần do đây là mực nước chết nên tích tụ nhiều cation kiềm.

Các $\mathrm{Mg}^{2+}$ nằm trong mức thấp dao động trung bình trong khoảng 0,41 - 0,93 (meq/100g) đất, trong cao trình CT2 (cao trình từ $190-195 \mathrm{~m}$ ) có hàm lượng $\mathrm{Mg}^{2+}$ thấp nhất 
là $0,41(\mathrm{meq} / 100 \mathrm{~g})$ đất, thấp hơn trung bình từ 2 - 2,3 lần, hai cao trình có hàm lượng $\mathrm{Mg}^{2+}$ bằng nhau cũng cao nhất là $\mathrm{CT} 1$ (mực nước $215 \mathrm{~m}$ ) với CT3 (mực nước 190 - 195m) trung bình giữa các vị trí đạt $0,93(\mathrm{meq} / 100 \mathrm{~g})$ đất, cao trình $\mathrm{CT} 4$ có hàm lượng $\mathrm{Mg}^{2+}$ ở mức trung bình giữa các vị trí lấy là $0,83(\mathrm{meq} / 100 \mathrm{~g})$ đất.

\section{KẾT LUẬN}

Quá trình lên xuống của mức nước, và độ dốc, dẫn đến tính chất đất tại các cao trình có thay đổi từ trên xuống, do sự sa lắng, xói mòn từ cao trình $215 \mathrm{~m}$ xuống các cao trình thấp hơn, nhưng tính chất cở đây cơ bản thể hiện độ pH chua, nghèo dinh dưỡng;
Ở hai cao trình CT1(cao trình NMCN 215m), và cao trình CT2 (cao trình $190-195 \mathrm{~m}$ ), thể hiện tính chất cơ bản là đất chua, nghèo dinh dưỡng, hàm lượng mùn, đạm có xu hướng tích tụ theo độ sâu, các phần cấp hạt, cation kiềm, ở mực thấp hơn các cao trình sau, hàm lượng $\mathrm{Al}^{3+}$, tăng dần đến cao trình CT2 (cao trình 190 - 195m).

Ở hai cao trình cuối CT3 (cao trình ngập từ $175-190 \mathrm{~m})$, và cao trình CT4 ( Cao trình $\mathrm{MNC} 175 \mathrm{~m}$ ), Thể hiện sự lắng đọng chất dinh dưỡng do vậy $\mathrm{pH}$, tăng dần, và các chất dinh dưỡng tăng dần đến mực nước chết, hàm lượng mùn, đạm có xu hướng tích tu giảm dần theo độ sâu, các phần cấp hạt, cation kiềm, giảm dần đến mực nước chết, hàm lượng $\mathrm{Al}^{3+}$, giảm dần.

\section{TÀI LIỆU THAM KHẢO}

1. Bộ Tài nguyên và Môi trường, Cục Bảo vệ Môi trường, Chương trình bảo tồn đa dạng sinh học vùng đất ngập nước sông Mekong (2006), Hệ thống phân loại đất ngập nước Việt Nam, Hà Nội;

2. Đỗ Xuân Đức, (2013). "Kinh nghiệm sử dụng tài nguyên gắn với bảo vệ môi truờngcủa cộng đồng người Thái tại ven hồ thủy điện Sơn La” Tạp chí Khoa học ĐHQGHN, Các Khoa học Trái đất và Môi trường, Tập 29, Số 3 (2013) 26-34.

3. Quyết định 198/QĐ_TTg, ngày 10 tháng 02 năm 2011. Quyết định về việc ban hành quy trình vận hành liên hồ chứa Sơn La, Hòa Bình, Thác Bà và Tuyên Quang trong mùa lũ hàng năm.

4. Thông tư 03/2012/TT - BTNMT, ngày 12 tháng 04 năm 2012. Quy định việc quản lý, sư dụng đất bán ngập nước lòng hồ thủy điện, thủy lơi;

5. Vũ Trung Tạng, (2004). “Nhũng quan điểm và sự phân loại ĐNN ở Việt Nam”, Tạp chí Khoa học, ĐHQGHN, KHTN\&CN. T.X.X, Số 3PT, tr. 58-65;

6. Viện Quy hoạch và Thiết kế Nông nghiệp (2007), Quy hoạch bố trí cơ cấu cây trồng hợp lý vùng bán ngập công trình Thuỷ điện Sơn La, Hà Nội. 